\title{
THE ECOLOGICAL INTERPRETATION OF UNBIASED ESTIMATOR FOR THE TAXONOMIC RATIO: DIFFERENT APPROACHES FOR LOCAL AND REGIONAL FLORA
}

\author{
OLEXANDER ZHUKOV $\bowtie$, LUDMILA ARABADZHY-TIPENKO \\ Bogdan Khmelnitsky Melitopol State Pedagogical University, Hetmanska st., 20, Melitopol, 72318, Ukraine; zhukov_dnipro@ukr.net \\ $\triangle$ Corresponding author
}

Received: 15 September 2020 / Accepted: 17 January 2021

Abstract

Zhukov O., Arabadzhy-Tipenko L.: The ecological interpretation of unbiased estimator for the taxonomic ratio: different approaches for local and regional flora. Ekológia (Bratislava), Vol. 40, No. 4, p. 348-356, 2021.

Taxonomic ratio in an ecological context is considered as an indicator of the level of competitive exclusion. In spite of more than a century of discussions on taxonomic ratio, the problem of finding an unbiased estimator for flora characterisation remains unsolved. The traditional form of taxonomic ratio (species/genus or species/families ratio) is biased, which depends on the area of territory for which the floral composition was established. This circumstance makes the taxonomic ratio an inadequate characteristic of the flora. To solve the problem of finding an unbiased estimator for the taxonomic ratio, we have combined two fundamental ecological generalisations. The first is that species that belong to the same genus usually live in similar habitats and have similar morphological features. The struggle for life between species from the same genus is, therefore, more intense than between species from different genera. The second is species-area relationship. We have considered the problem of finding an unbiased taxonomic relationship using the Arrhenius curves to fit species-area relationships. This combination allowed us to find a form of unbiased taxonomic relationship. The example of Cyanophyceae flora shows that this indicator is closely related to a wide range of ecological and biogeographical characteristics of vegetation. The residual of the linear equation of dependence of the logarithm of the number of species on the logarithm of the number of genera is an unbiased indicator of the taxonomic relation, which is independent of the number of genera (or number of families) and the sampling size (or area). An unbiased taxonomic relationship is a characteristic of regional flora, which depends on a wide range of its ecological and biogeographical features.

Key words: biodiversity, competitive exclusion, species/area ratio, ecological groups, geographical distribution.

\section{Introduction}

Taxonomic ratios (ratio of the number of species to the number of genera or families) are used in ecology to use evolutionary arguments to explain the ecological features (He, 2005; Hubbell, 2001; Rosindell et al., 2011). Darwin noted that species that belong to the same genus typically live in the same habitat and have similar morphological features. The struggle for life between species from the same genus will, therefore, be more intense than that between species from other genera (Darwin, 1859). Taxonomic ratios are seen as an indicator of the level of competitive exclusion (Elton, 1946). Close species should not coexist for long periods because of the shared resources they use (Elton, 1946; Enquist et al., 2002; Strong, 1980; Williams, 1947). To test this hypothesis, Paul Jaccard proposed a 'generic coefficient' that was applied to describe biogeographical patterns and to measure the impact of competition on diversity (Jaccard, 1901). Palmgren related changes in the generic coefficient to random sampling effects (Palmgren, 1921). In 1929, this factor was criticised by A. Maillefer for the fact that the factor depends on the size of the accounting area or the area within which the flora is considered
(Maillefer, 1929). In 1941, Jaccard responded to the criticism and noted that area alone cannot explain the difference between the values of the generic coefficient of different plant communities and insisted on his vision of the coefficient as a measure of the ecological properties of flora (Jaccard, 1941). It has been shown that where the distribution of species and genera is subject to the distribution of log series, the genus factor is a function of the community diversity index (Williams, 1949).

An important generalisation of island biogeography is that the species:genus ratio for island flora and fauna is always lower than for areas that are sources of replenishment of island biodiversity (MacArthur, Wilson, 1967). Two alternative explanations were discussed for the interpretation of this result. These are interpretations of the genus ratio as a marker of similarity between species, or only as a statistical artefact. Indeed, it was shown that random samples are always characterised by a lower genus ratio than the total sample that generates them (Williams, 1964). The relative number of species should be smaller relative to the number of genera, provided there is high intensity of competition. But as a quantitative parameter of flora, the taxonomic ratio is a biased measure depending on the number of species (Gotelli, Colwell, 2001). 
The species/genus ratio is traditionally interpreted as an indicator of the intensity of competitive exclusion: species of the same genus are characterised by similar requirements to environmental conditions, so they will be involved in relations of a higher level of competition (Krug et al., 2008). A number of studies show that taxonomic ratios do not differ from the zero alternative (Chase, Leibold, 2003; Simberloff, 1970). Some studies have found that the number of species of the same genus is greater than the random alternative (Daehler, 2001; Enquist et al., 2002; Tofts, Silvertown, 2000). The species/genus ratio for freshwater fish parasite fauna is significantly higher than for marine fish parasites, indicating fundamental differences in the patterns of freshwater parasite fauna diversity relative to the marine environment (Poulin, 2016). The higher taxonomic ratio is interpreted as an indicator of a higher level of competition within the taxonomic genus for Bryozoa (Figuerola et al., 2017).

The species/genus ratio is so sensitive to diversity that the zero alternative increases with the number of species in the flora or fauna (Gotelli, Colwell, 2001; Jarvinen, 1982; Simberloff, 1970). Taxonomic ratios may reflect features of the phylogenetic development of the taxonomic structure as well as the potential for dispersal of marine bivalve molluscs (Krug et al., 2008). It has been shown that the taxonomic ratio of marine molluscs significantly increases in latitude gradient, even with a rapid reduction in the number of species with increasing latitude (Roy, 1996).

The relationship between the number of species and the number of genera can be described after logarithm transformation by a linear model (Palmer et al., 2008):

$$
\log (\text { species })=b_{0}+b_{1} \log (\text { genera })+e
$$

where species - the number of species, genera - the number of genera and $b_{0}$ та $b_{1}$ - regression coefficients. For North American flora, no clear trends in the number of species and genera with latitude have been found, but the residuals of this model show a clear dependence on latitude (Palmer et al., 2008). The number of species is a growing function of area - this is one of the most important generalisations of ecology (Arrhenius, 1921; Connor, McCoy, 1979; Fisher et al., 1943; Gleason, 1922; Preston, 1960). The Arrhenius generalisation (Arrhenius, 1921) indicates degree dependence between the area and the number of species: $S=\mathrm{c}$ $A^{z}$, where $S$ is the number of species, $A$ is the area and c and $z$ are the coefficients. The Arrhenius formula is the best model for the biogeographical scale both empirically and theoretically (Rosenzweig, 1995; Fridley et al., 2005, 2006).

Despite almost more than a century of discussion about the taxonomic ratio, the problem of finding an unbiased estimator of the flora characteristics remains unresolved. To solve it, we combined two fundamental environmental generalisations. We considered the problem of finding an unbiased taxonomic ratio through the prism of diversity/area dependence. This combination allowed us to find a form of unbiased taxonomic ratio. The example of the flora of Cyanophyceae shows that this indicator is closely related to a wide range of ecological and biogeographical characteristics of vegetation.

\section{Methods}

Cyanophyceae studies were conducted within the Pryazovskyi National Natural Park. On the territory of Pryazovskyi Park, nine experimental polygons were identified, which covered the steppe areas or slopes, salt marshes, coastal sandy soils and ponds (rivers, lakes, estuaries, sea bays, lagoons). One hundred and twenty-four algological individual and united water and soil samples served as the material for the study on Cyanophyceae. Sampling was carried out in the spring-winter period during the routine surveys carried out in 2013-2019. Ecological and biogeographical analysis of the identified species was conducted on the basis of the information given in the monograph O. M. Vinogradova (Vinigradova, 2012), as well as with the help of literary sources devoted to the algae of Ukraine and other countries (Kostikov et al., 2001; Whitton, 2012). According to the preferred salinity conditions of the environment, Cyanophyceae are divided into halotolerant, halobiont, halophilic and marine ecological groups (Komárek, Anagnostidis, 1999). The marine species occupy an intermediate position between the halophilic and halotolerant groups. According to the criterion of preferences of salinity given under the classification of O. M. Vinogradova (Vinigradova, 2012), we divided the investigated flora into: stenotopic halotolerant (freshwater forms according to O. M. Vinogradova), euritopic halotolerant (all other halotolerant forms according to O. M. Vinogradova), halobiont and halophilic. According to the preferred salinity conditions of the environment, the ecological groups of Cyanophyceae can be quantified as follows: stenotopic halotolerant (freshwater) - 1 , euritopic halotolerant -2 , halobiont -3 and halophilic -4 . An ecotope salinity indicator based on the information on the structure of the Cyanophyceae community would be as follows:

$$
\text { Halo }=\frac{1}{S} \sum_{i=1}^{N} \frac{G L_{i}}{S_{i}}
$$

where Halo - phytoindication assessment of salinity of the ecotope for Cyanophyceae community; $S$ - total number of species in the community; $i$ - serial number of the environmental group by preference given to the conditions of salinity, $N$ - total number of such groups and $S_{i}$ - the number of species belonging to the relevant environmental group. Thus, the phytoindicative assessment of salinity of the ecotope for Cyanophyceae community (Halo) can vary from 1 to 4 . Level 1 corresponds to a fresh pond without signs of salinity and level 4 corresponds to the most saline ecotopes.

According to the spatial coverage of the range of Cyanophyceae, the regional flora can be divided into the following groups: European temperate zone inhabitants, European species, Eurasian species, circumcontinental or circumoceanic and cosmopolitan. Consequently, the range width of species can be conventionally characterised as: 1 - species with a narrow range within the temperate zone, 2 - European species, 3 - range covers Europe and Asia, 4 - species of circumcontinental or circumoceanic distribution and 5 - cosmopolitans. The indicator of geographical distribution of community species by the arealological structure of Cyanophyceae can be calculated as follows:

$$
\text { Geogr }=\frac{1}{S} \sum_{i=1}^{N} \frac{G r_{i}}{S_{i}}
$$

where Geogr -assessment of geographical distribution of Cyanophyceae community species; $S$ - total number of species 


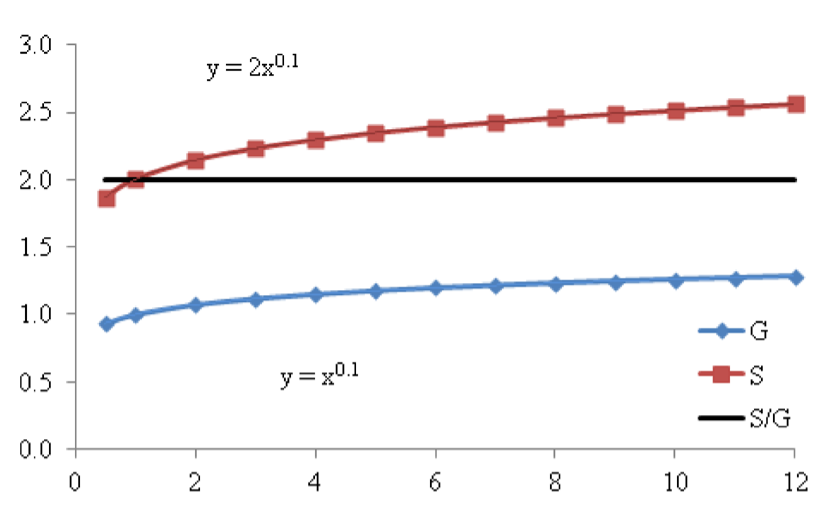

A

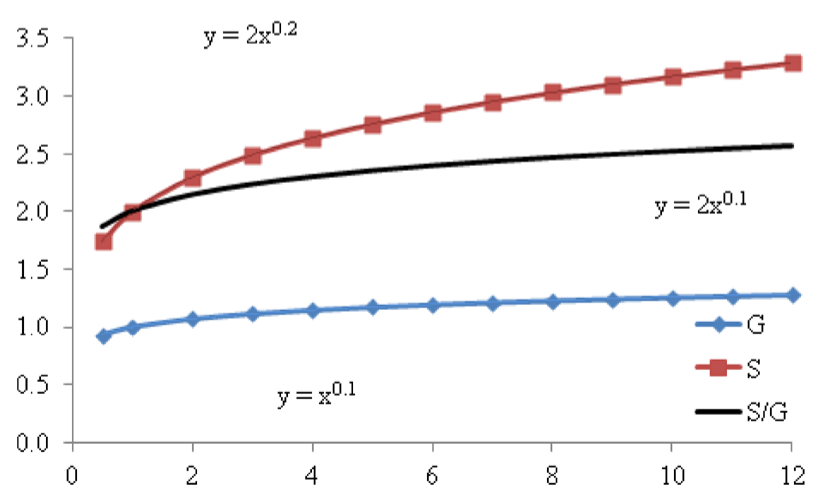

B

Fig. 1. Results of numerical modelling of dependence between the number of species and genera on area and dynamics of taxonomic ratio. Here abscissa is area (conventional units); ordinate is number of species (S), number of genera $(\mathrm{G})$ and taxonomic ratio of number of species to number of genera $(\mathrm{S} / \mathrm{G})$.

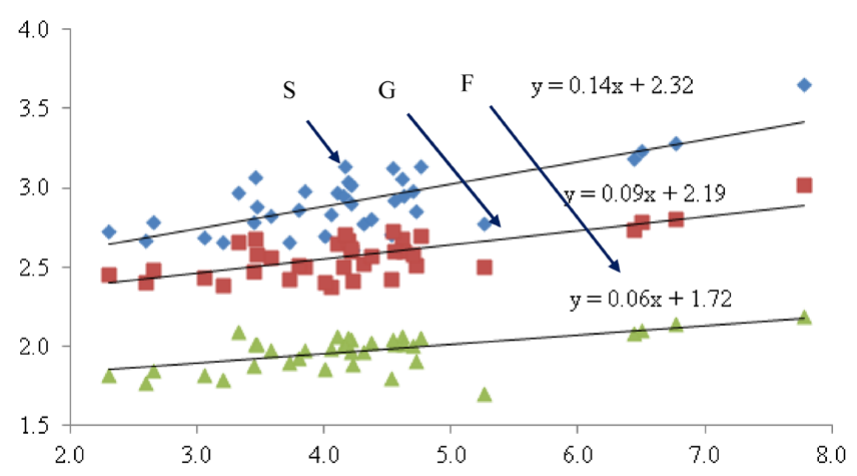

Fig. 2. Relationship between area and the number of species (S), genera $(G)$ and families (F) for the flora of vascular plants in Ukraine. Axis abscissa is the area, ha (decimal logarithm); axis ordinate is the number of taxa of the corresponding level (decimal logarithm). Formulas indicate linear approximations of the dependence of the number of taxa on the area by the method of least square. in the community; $i$ - serial number of the arealogical type; $N$ - total number of such types; $S_{i}$ - number of species belonging to the respective arealogical type and $G r_{i}$ - range width of species $(1-$ species with a narrow range within the temperate zone, 2 - European species, 3 - range covers Europe and Asia, 4 - species with a wide range, but not cosmopolitan, 5 - cosmopolitan).

\section{Results}

\section{Unbiased estimator of the taxonomic ratio}

It can be assumed that there is a dependence of the number of genera on the area, which can be described by a power function. Then, according to the Arrhenius formula, for the number of species and the number of genera, the following dependencies will be correct:

$$
\begin{aligned}
& S=c_{1} A^{z_{1}} \\
& G=c_{2} A^{z_{2}}
\end{aligned}
$$

where $S$ - the number of species; $G$ - the number of genera; $A$ area and $c_{1}, c_{2}, z_{1}, z_{2}$ - coefficients.

The taxonomic ratio of the number of species to the number of genera can be derived as follows:

$$
\frac{S}{G}=\frac{c_{1}}{c_{2}} A^{z_{1}-z_{2}}
$$

Thus, the taxonomic ratio is a constant characterising the flora and does not depend on the area of the investigated territory only under the condition $z_{1}=z_{2}$, that is, if the growth rates of the number of species and number of genera with the growth of the area are equal. This situation is illustrated in Fig. 1, but the most probable situation is when the rate of species and genus growth is different, and in this case, the taxonomic ratio will be an indicator, which depends both on the properties of the flora and the area of the territory (Fig. 2). Thus, the taxonomic ratio has a bias, which depends on the area of territory for which the floral composition is determined. This fact makes the taxonomic relation an inconsistent characteristic of the flora. The following transformations allow us to find the level of estimation bias and take it into account when characterising flora.

Logarithmic equations allow us to obtain:

$$
\log S=\log c_{1}+z_{1} \log A \text { та } \log G=\log c_{2}+z_{2} \log A,
$$

$$
\frac{\log S-\log c_{1}}{z_{1}}=\log A \text { and }
$$

$$
\frac{\log G-\log c_{2}}{Z_{2}}=\log A
$$


It allows us to obtain an expression that does not contain the area:

$$
\frac{\log S-\log c_{1}}{z_{1}}=\frac{\log G-\log c_{2}}{z_{2}}
$$

We get rid of the denominator in the equation:

$$
z_{2} \log S-z_{2} \log c_{1}=z_{1} \log G-z_{1} \log c_{2},
$$

where does the logarithm of the number of species equal:

$$
\log S=\frac{z_{1}}{z_{2}} \log G+\log c_{1}-\frac{z_{1}}{z_{2}} \log c_{2} .
$$

It is worth considering that $\frac{z_{1}}{z_{2}}$ is constant, so it is reasonable to replace $\frac{z_{1}}{z_{2}}=K$; also, is constant, so we can write down $\log c_{1}-\frac{z_{1}}{z_{2}} \log c_{2}=$ const $+\varepsilon$. Accordingly, we get a linear dependence:

$$
\log S=K \log G+\text { const }+\varepsilon
$$

where $K$ and const are coefficients of the linear regression and $\varepsilon$ is a residual of the linear regression.

It is not difficult algebraic transformations (10) that drive us the taxonomic ratio has the form:

$$
\frac{\log S}{\log G}-\frac{\text { const }+\varepsilon}{\log G}=K
$$

Thus, the taxonomic ratio is a constant that characterises only the flora and does not depend on other factors, only if the correction is taken away from this ratio $\frac{\text { const }+\varepsilon}{\log G}$. Now, let us find out under what conditions the taxonomic ratio will be a constant that characterises the flora and does not depend on the number of species or genera. For this purpose, let us assume that if $G \rightarrow$ $\infty$ (i.e. the number of genera is 'very large'), then $\frac{\text { const }+\varepsilon}{\log G} \rightarrow 0$ and we can assume $\frac{\log S}{\log G} \approx K$. That is, for the unrealistic, large regional flora, the ratio of the logarithm of the number of species to the logarithm of the number of genera (or to the logarithm of the number of families) is practically a constant, which characterises this flora. The physical sense of this relation consists of the fact that it characterises relative rate of the growth of number of taxa with increase in area. If the number of genera (or families) is insignificant, that is, in the situation with local flora, then the ratio of logarithms will be a biased estimation, which depends very much on the floristic diversity and area of territory.

It is obvious that the coefficients $K$ and const characterise the regional flora as a whole, as they can be found on the basis of the data on local flora, which make up the regional flora. The characteristic of the local flora can be the residual of the global regression dependence $\varepsilon$ containing two components - information noise and the local component of variation, which is a specific characteristic of the local flora:

$\log S-K \log G-$ const $=\varepsilon$, whereto get it from

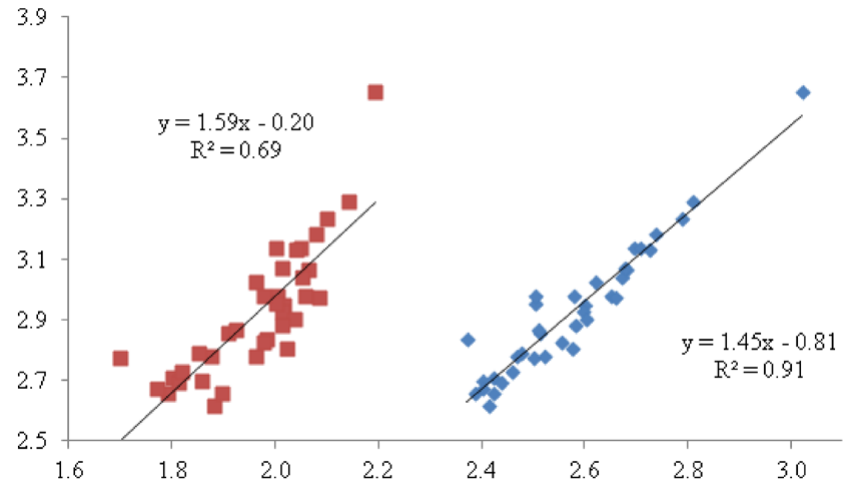

Fig. 3. Dependence of the number of species on the number of genera or families in the flora of vascular plants of Ukraine. The abscissa axis is the number of genera $(\mathrm{G})$ or families (F) (decimal logarithms), the ordinate axis is the number of species (decimal logarithm).

$$
\log \left(\frac{S}{G^{K}}\right)-\text { const }=\varepsilon, \text { which allows to get }
$$

$$
\frac{S}{G^{K}}=10^{\text {const }+\varepsilon}
$$

Thus, with the accuracy of statistical error, an unbiased characteristic of the flora is not the taxonomic relation itself, but the ratio of the number of species to the number of genera raised to a power that is numerically equal to the ratio of the growth rate of the number of species to the growth rate of the number of genera with the area. The regression coefficients $K$ and const can be estimated on the basis of the information on global flora and, consequently, the taxonomic ratio for the local flora cannot be found in unbiased form if the properties of global flora are unknown.

\section{Taxonomic ratio for the flora of Ukraine}

The dependencies of the number of species on the number of genera or the area of the territory are most often considered in the context of island biogeography problems due to the obvious and clear spatial dimensions of the areas for which flora or fauna characteristics are defined. For terrestrial ecosystems, there are well-documented species lists for administrative areas - countries or regions - and for protected areas (Appendix 1). Areas of relevant sites are clearly defined. Analysis of dependence of the number of taxa on the area for flora and vascular plants of Ukraine confirms the assumption that with an increase in area in the logarithmic scale, the number of taxa grows linearly; growth occurs the fastest for the number of species, less quickly for the number of genera and quite slowly for families (Fig. 2). The slope angles of corresponding dependencies are considerably different; therefore, the assumption about invariance of the taxonomic ratio cannot be confirmed. As it was supposed, there is a linear dependence between the number of species and the number of genera or families on logarithmic scale (Fig. 3). Coefficients $\mathrm{K}$ are equal to 1.59 and 1.45 , respectively. It should be noted that the ratio of the number of species to the number of genera and 


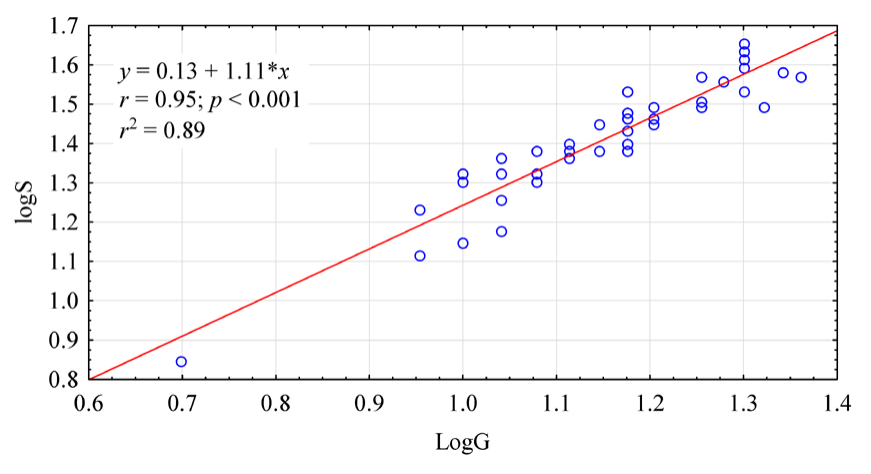

Fig. 4. Dependence of the number of regional flora species of Cyanophyceae on the number of genera. The abscissa axis is the number of genera (decimal logarithm), the ordinate axis is the number of species (decimal logarithm).

Table 1. Multiple regression analysis of residuals of dependence of the number of species on the number of genera $\left(R_{\text {adj }}{ }^{2}=0.87, p<\right.$ $0.001)$. Standardised regression coefficients are presented.

\begin{tabular}{|l|l|l|}
\hline Predictor & $b \pm$ st. error & $p$-value \\
\hline $\begin{array}{l}\text { Indicator of the level of salinity } \\
\text { of ecotopes }(\mathrm{H})\end{array}$ & $4.91 \pm 0.82$ & $<0.001$ \\
\hline $\begin{array}{l}\text { Indicator of geographical range } \\
\text { of species in a community (G) }\end{array}$ & $1.79 \pm 0.49$ & $<0.001$ \\
\hline $\mathrm{H}^{2}$ & $-4.93 \pm 0.80$ & $<0.001$ \\
\hline $\mathrm{G}^{2}$ & $-2.05 \pm 0.48$ & $<0.001$ \\
\hline Aerophyte & $0.17 \pm 0.07$ & 0.017 \\
\hline Aquale & $-0.31 \pm 0.13$ & 0.022 \\
\hline Aquale-subaerophyte & $-0.27 \pm 0.10$ & 0.007 \\
\hline Aquale-terrestrial & $-0.12 \pm 0.07$ & 0.088 \\
\hline Eurybiont & $0.27 \pm 0.07$ & $<0.001$ \\
\hline Subaerophyte & $-0.41 \pm 0.09$ & $<0.001$ \\
\hline Terrestrial & $-0.34 \pm 0.08$ & $<0.001$ \\
\hline Terrestrial-subaerophyte & $-0.50 \pm 0.10$ & $<0.001$ \\
\hline & & \\
\hline
\end{tabular}

families statistically significantly correlates with area $(r=0.68$, $p<0.001$ та $r=0.72, p<0.001$, respectively). Thus, taxonomic ratio significantly depends on area. In turn, $\mathrm{S} / \mathrm{G}^{\mathrm{K}}$ and $\mathrm{S} / \mathrm{F}^{\mathrm{K}}$ ratios are predictably independent of area $(r=0.17, p=0.32$ та $r=0.22$, $p=0.19$, respectively).

Thus, dependence of the number of species on the number of higher taxa (genera, families) is a characteristic of the flora as a whole and is a tool to recalculate the number of species depending on the surveyed area, which is presented in a clear or latent form.

\section{Taxonomic ratio for Cyanophyceae flora}

For the flora of Cyanophyceae, a linear dependence between the number of species and the number of genera in the logarithmic scale was also found (Fig. 4). The dependence is able to explain $89 \%$ of the variation of the studied characteristic. The S/G ratio statistically significantly correlates with the number of species $(r$ $=0.53, p<0.001)$, while the $\mathrm{S} / \mathrm{G}^{\mathrm{K}}$ ratio does not depend statisti- cally on the number of species $(r=0.24, p=0.10)$ and the number of genera $(r=-0.11, p=0.45)$.

The local flora is described by the residuals from the linear dependence of the logarithm of the number of species on the logarithm of the number of genera. These residuals comprise $11 \%$ of the variability in the logarithm of the number of species. In turn, $87 \%$ of variation of residuals can be explained by the level of salinity of ecotopes, which is an indicator of geographical range of species in a community and a marker of preferential habitat (Table 1).

The level of salinity of ecotopes naturally affects the ratio of species to the number of genera. This dependence has a nonlinear character, as evidenced from the regression coefficients and can also be illustrated graphically (Fig. 5). In general, with increasing salinity levels, the ratio of number of species to the number of genera increases, but with very high salinity levels, there is a sharp decline. Also, dependence of taxonomic ratio on the width of geographical distribution of species is non-linear. The increase in the community of widely distributed species contributes to the growth of the ratio to a certain level. In communities that are predominantly species with wide ranges, the taxonomic ratio decreases. The increase in the community of aerophytes, aquatic and terrestrial forms contributes to the growth of taxonomic ratio.

\section{Discussion}

The taxonomic ratio was widely used over a long period of time as a quantitative indicator of the community structure. Its main idea is to assess the differences or similarities of species in a community and to find out the role of interspecific competition in community formation. Taxonomic ratios are consistent with the intuitive notion that the number of species does not fully reflect the diversity of a community. The number of species and its derivatives diversity indices (Shannon, Simpson, etc.) do not take into account differences between species in a community, namely such differences are a source of diversity in a community (Magurran, 2004; Pielou, 1969). Similarity of species in a community is an indirect sign of the degree of competitive interaction and can be used to test hypotheses about the role of competition in community structuring (Roughgarden, 1983). Species/genus or species/family ratio is used to describe the level of interspecific competition at the community level (MacArthur, Wilson, 1967). Low taxonomic ratios can be explained by the high level of competition between species within genera (Elton, 1946). However, in small samples, regardless of the level of competition among the community, the taxonomic ratio will be naturally lower (Simberloff, 1970).

It has been shown that the number of species with increasing sample size increases faster than the number of genera, resulting in a shift in the ratio that depends on sample size (Colwell, 2000; Gotelli, Colwell, 2001). The known spatial dependency of the number of species (Arrhenius, 1921) can be rephrased to mean that increased sampling efforts result in the identification of more species (Gotelli, Chao, 2013). Thus, an increase in geographical coverage of an area could be seen as an increase in data collection efforts that provide more complete estimates of the number of species and taxa of higher order. The application of the Arrhenius model to simulate the behaviour of the number of taxa at different levels depending on area 


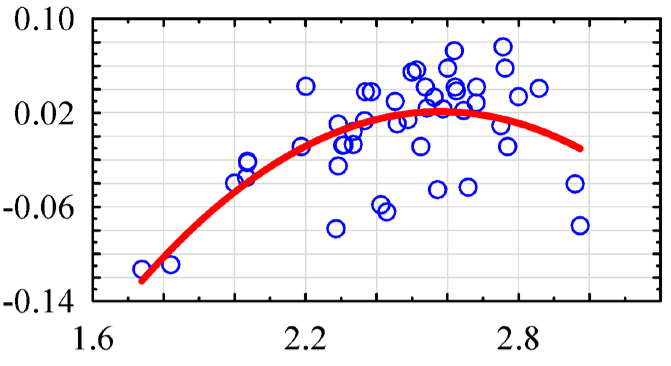

A
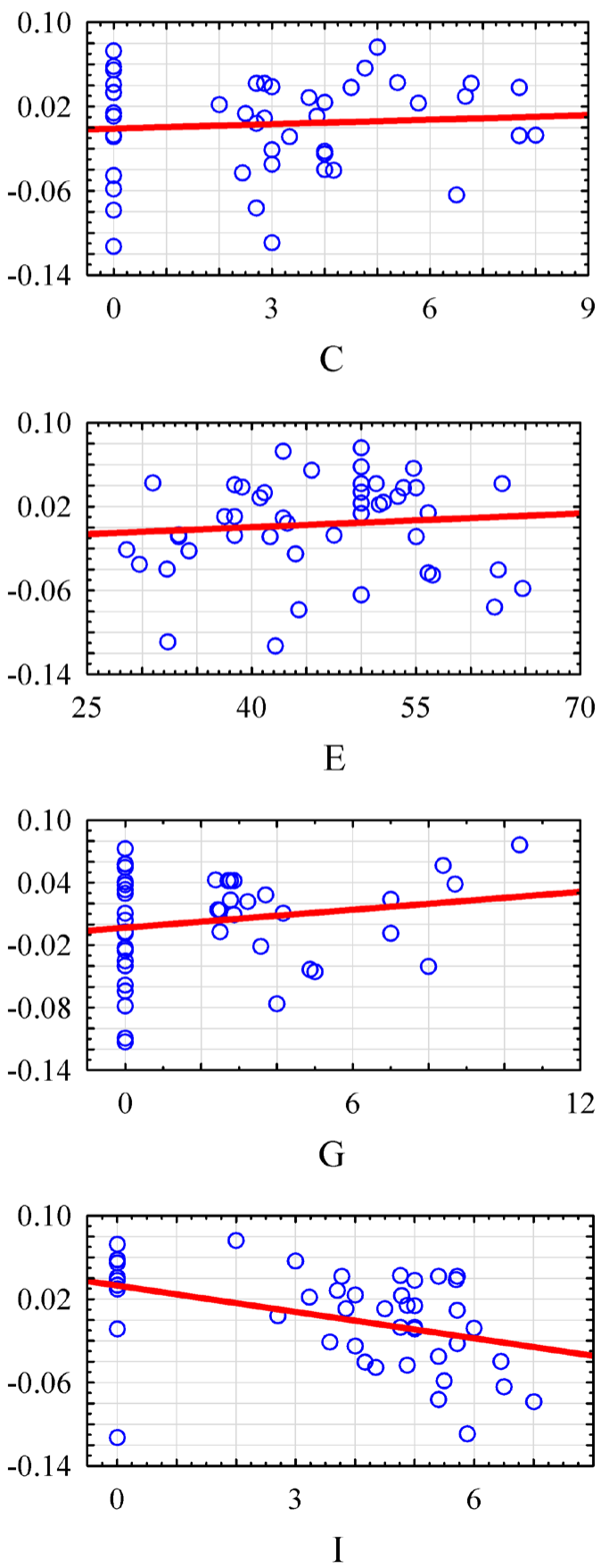

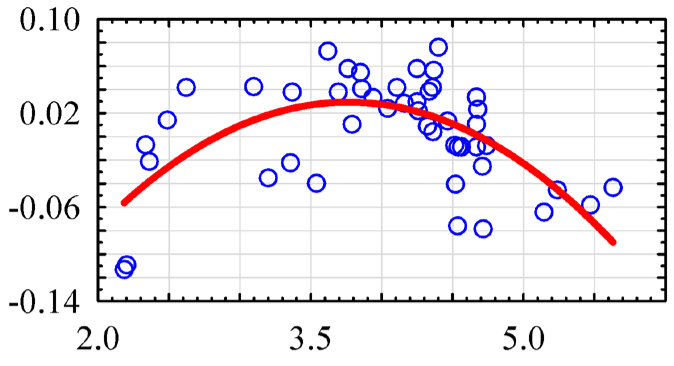

B
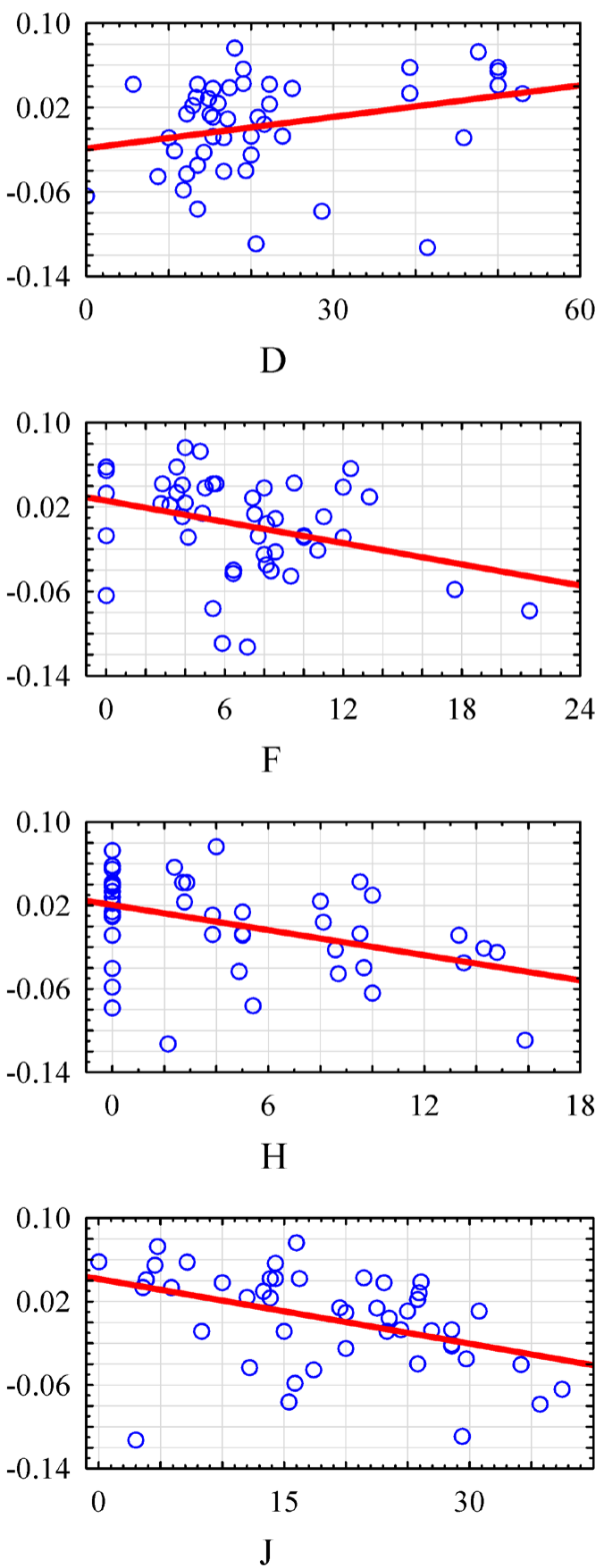

Fig. 5. Dependence of regression residues of the number of species on the number of genera based on the level of salinity of ecotopes (A), the level of geographical distribution of species (B), the proportion in the group of aerophyte (C), aquatic forms (D), aquale-subaerophyte forms (E), aquale-terrestrial forms $(\mathrm{F})$, eurybionts $(\mathrm{G})$, subaerophyte $(\mathrm{H})$, terrestrial forms (I) and terrestrial-subaerophyte forms $(\mathrm{J})$. 
(or the intensity of effort for collecting) has resulted in a form of taxa of different rank. It is established that not the ratio of taxa, but the ratio of logarithm of taxa possesses the best properties for description of flora. This ratio for rather large samples does not depend on the size of a sample and can be used for the solution of some problems for which the taxonomic ratio was initially applied. In small samples, the ratio will give systematically underestimated results. Also, the best form of taxonomic ratio can be considered $\frac{S}{G^{K}}$, which $K$ allows to get an indicator that does not depend on the sample size. This coefficient can be estimated on the basis of regression dependence for the whole regional flora. This ratio has the desired property - independence from sample size (or area) - and can be applied to compare local flora and plant communities. But according to equation (14), this ratio is quantitatively equal to the exponential sum of the constant, which is common to the flora as a whole, and the variable, which is specific to the local flora and the random variables. Therefore, the best characteristic of taxonomic ratios is the residual of equation (10). The residual of equation (10) can be considered as an unbiased indicator of taxonomic relations, which is normalised to the number of genera (or number of families) and to the sample size (or area).

The practical application of the obtained results consists in the fact that the proposed quantitative indicators of the taxonomic ratio are unbiased estimates, on the basis of which it is possible to statistically test hypotheses for comparison of different flora and about the influence of different factors on the taxonomic ratio. An effective statistical tool for testing hypotheses is very important for monitoring taxonomic diversity in the context of anthropogenic influence and global climate change at different spatial and hierarchical levels of biota organisation.

\section{Conclusion}

The taxonomic ratios in the traditional form are biased characteristics of the flora, which depend on the diversity of flora at the level of genera/families and the area of the investigated territory. Only for large regional flora, the ratio of logarithm of number of species to logarithm of number of genera (or to logarithm of number of families) is unbiased index, which characterises this flora in a meaningful way. Thus, for traditional floristic researches, it is reasonable to use as a quantitative indicator the taxonomic ratio in the form of the ratio of logarithm of number of species to logarithm of number of corresponding taxa (genus or families). If the number of genera (or families) is insignificant in comparison with regional flora, which is the case for local flora or plant communities, then this indicator will be a biased estimate, which will largely depend on floral diversity and area. An unbiased floral characteristic is the ratio of the number of species to the number of genera that is raised to some power. This power is nothing more than a ratio of the rate at which the number of species and genera increases with area. This power is regionspecific and specific to regional flora. Thus, there is no universal form of taxonomic ratio as unbiased floral characteristic. The residuals of the linear equation of dependence of logarithms of the number of species on logarithms of the number of genera are the unbiased evaluation of the taxonomic ratio, which does not depend on the number of genera (or number of families) and the sampling size (or area). An unbiased taxonomic ratio is a characteristic of local flora that is ecologically relevant. It is confirmed by the fact that this indicator depends on a wide range of ecological and biogeographical features of the flora.

The results obtained indicate that different forms for quantitative description of taxonomic ratio should be used to solve the problems of flora and plant communities' characteristics. For flora description, it is correct to use the ratio of logarithms of number of corresponding taxa (ratio of logarithms of number of species to logarithms of number of genera or families). To describe the taxonomic ratio in local flora or in a community of plants, it is necessary to sample from regional flora to construct regression dependence of logarithms of number of species on logarithms of number of genera (or families). The residual of this model will be an unbiased taxonomic ratio characteristic for the local flora or plant community.

\section{References}

Arrhenius, O. (1921). Species and area. The Journal of Ecology, 9(1), 95. DOI: $10.2307 / 2255763$.

Chase, J.M. \& Leibold M.A. (2003). Ecological niches: Linking classical and contemporary approaches. Chicago: University of Chicago Press.

Colwell, R.K. (2000). Rensch's rule crosses the line: Convergent allometry of sexual size dimorphism in hummingbirds and flower mites. American Naturalist, 156(5), 495-510. DOI: 10.1086/303406.

Connor, E.F. \& McCoy E.D. (1979). The statistics and biology of the species-area relationship. American Naturalist, 113(6), 791-833. DOI: $10.1086 / 283438$.

Daehler, C.C. (2001). Darwin's naturalization hypothesis revisited. American Naturalist, 158(3), 324-330. DOI: 10.1086/321316.

Darwin, C. (1859). On the origin of species by means of natural selection, or The preservation of favoured races in the struggle for life. London: John Murray. DOI: 10.5962/bhl.title.68064.

Elton, C. (1946). Competition and the structure of ecological communities. The Journal of Animal Ecology, 15(1), 54. DOI: 10.2307/1625.

Enquist, B.J., Haskell, J.P. \& Tiffney B.H. (2002). General patterns of taxonomic and biomass partitioning in extant and fossil plant communities. Nature, 419(6907), 610-613. DOI: 10.1038/nature01069.

Figuerola, B., Barnes, D.K.A., Brickle, P. \& Brewin P.E. (2017). Bryozoan diversity around the Falkland and South Georgia Islands: Overcoming Antarctic barriers. Marine Environmental Research, 126, 81-94. DOI: 10.1016/j.marenvres.2017.02.005.

Fisher, R.A., Corbet, A.S. \& Williams C.B. (1943). The relation between the number of species and the number of individuals in a random sample of an animal population. The Journal of Animal Ecology, 12(1), 42. DOI: $10.2307 / 1411$.

Fridley, J.D., Peet, R.K., Wentworth, T.R. \& White P.S. (2005). Connecting fine- and broad-scale species-area relationships of southeastern U.S. flora. Ecology, 86(5), 1172-1177. DOI: 10.1890/03-3187.

Fridley, J.D., Qian, H., White, P.S. \& Palmer M.W. (2006). Plant species invasions along the latitudinal gradient in the United States: comment. Ecology, 87, 3209-3213. DOI: 10.1890/0012-9658(2006)87[3209:psiatl] 2.0.co.

Gleason, H.A. (1922). On the relation between species and area. Ecology, 3(2), 158-162. DOI: $10.2307 / 1929150$.

Gotelli, N.J. \& Chao A. (2013). Measuring and estimating species richness, species diversity, and biotic similarity from sampling data. In S.A. Levin (Ed.), Encyclopedia of biodiversity (pp. 195-211). Waltham: Academic Press. DOI: 10.1016/B978-0-12-384719-5.00424-X.

Gotelli, N.J. \& Colwell R.K. (2001). Quantifying biodiversity: procedures and pitfalls in the measurement and comparison of species richness. Ecology Letters, 4(4), 379-391. DOI: 10.1046/j.1461-0248.2001.00230.x.

He, F. (2005). Deriving a neutral model of species abundance from fundamental mechanisms of population dynamics. Functional Ecology, 19(1), 187-193. DOI: 10.1111/j.0269-8463.2005.00944.x.

Hubbell, S.P. (2001). The unified neutral theory of biodiversity and biogeography. Princeton: Princeton University Press. 
Jaccard, P. (1901). Étude comparative de la distribution florale dans une portion des Alpes et des Jura. Bulletin de La Société Vaudoise Des Sciences Naturelles, 37, 547-579.

Jaccard, P. (1941). Sur le coefficient generique. Chronica Botanica, 6(16), $361-364$.

Jarvinen, O. (1982). Species-to-genus ratios in biogeography: A historical note. Journal of Biogeography, 9(4), 363. DOI: 10.2307/2844723.

Khannanova, O.R. (2015). The systematic analysis of the flora of the regional landscape park «Gadyachsky» (Poltava region, Ukraine). Chornomorski Botanical Journal, 11(3), 364-372. DOI: 10.14255/2308-9628/15.113/9.

Komárek, J. \& Anagnostidis K. (1999). Cyanoprokaryota. I. Chroococcales. In H. Ettl, G. Gärtner, H. Heynig \& D. Mollenhauer (Eds.), Süßwasserflora von Mitteleuropa (pp. 1-548). Heidelberg, Berlin: Spektrum, Akademischer Verlag.

Kostikov, I.Y., Romanenko, P.O., Demchenko, E.M., Darienko, T.M., Mikhailyuk, T.I., Rybchynskyi, O.V. \& Solonenko A.M. (2001). The soil algae from Ukraine (history and methodsof investigation, classification system, list of taxa) (in Ukrainian). Kyiv: Phytosociocenter.

Krug, A.Z., Jablonski, D. \& Valentine J.W. (2008). Species-genus ratios reflect a global history of diversification and range expansion in marine bivalves. Proceedings of the Royal Society B: Biological Sciences, 275(1639), 1117-1123. DOI: 10.1098/rspb.2007.1729

MacArthur, R.H. \& Wilson E.O. (1967). The theory of island biogeography. Princeton: Princeton University Press.

Magurran, A.E. (2004). Measuring biological diversity. Blackwell Science Ltd.

Maillefer, A. (1929). Le Coefficient générique de P. Jacard et sa signification. Mémoires de La Société Vaudoise Des Sciences Naturelles, 3(4), 113-183. DOI: $10.5169 /$ seals-249679.

Melnychuk, S. \& Trochymenko G. (2017). Floristic richness and taxonomic analysis of the flora of the national park "biloberezhzhya svyatoslava." ScienceRise: Biological Science, 2(5), 24-29. DOI: 10.15587/2519. 8025.2017.99760

Onyshchenko, V.A. \& Andrienko T.L. (Eds.) (2012a). Phytodiversity of nature reserves and national nature parks of Ukraine. Part 1. Biosphere reserves. Nature reserves (in Ukrainian). Kyiv: Phytosociocenter.

Onyshchenko, V.A., \& Andrienko T.L. (Eds.). (2012b). Phytodiversity of nature reserves and national nature parks of Ukraine. Part 2. National nature parks (in Ukrainian). Kyiv: Phytosociocenter

Palmer, M.W., McGlinn, D.J. \& Fridley J.D. (2008). Artifacts and artifictioxns in biodiversity research. Folia Geobotanica, 43(3), 245-257. DOI $10.1007 /$ s12224-008-9012-y.

Palmgren, M.O. (1921). Die Entfernung als pflanzengeographischer Faktor (Isolation as a phytogeographical factor). Series Acta Societatis pro Fauna et Flora Fennica, 49(1), 1-113.
Pielou, E.C. (1969). An introduction to mathematical ecology. Wiley-Interscience.

Poulin, R. (2016). Greater diversification of freshwater than marine parasites of fish. International Journal for Parasitology, 46(4), 275-27 DOI: 10.1016/j.ijpara.2015.12.002.

Preston, F.W. (1960). Time and space and the variation of species. Ecology, 41(4), 611-627. DOI: 10.2307/1931793.

Rosenzweig, M.L. (1995). Species diversity in space and time. Cambridge: Cambridge University Press.

Rosindell, J., Hubbell, S.P. \& Etienne R.S. (2011). The unified neutral theory of biodiversity and biogeography at age ten. Trends in Ecology \& Evolution, 26(7), 340-348. DOI: 10.1016/j.tree.2011.03.024.

Roughgarden, J. (1983). Competition and theory in community ecology American Naturalist, 122(5), 583-601. DOI: 10.2307/2460842.

Roy, K. (1996). Higher taxa in biodiversity studies: patterns from eastern Pacific marine molluscs. Philosophical Transactions of the Royal Society of London. Series B: Biological Sciences, 351(1347), 1605-1613. DOI 10.1098/rstb.1996.0144.

Simberloff, D.S. (1970). Taxonomic diversity of Island biotas. Evolution, 24(1), 23. DOI: $10.2307 / 2406712$.

Strong, D.R. (1980). Null hypotheses in ecology. Synthese, 43(2), 271-285. DOI: $10.1007 / \mathrm{BF} 00413928$.

Tarasov, V.V. (2012). Dnipropetrovsk and Zaporizhia regions flora (in Ukrainian). Dnipropetrovsk: Lira.

Tofts, R. \& Silvertown J. (2000). A phylogenetic approach to community assembly from a local species pool. Proceedings of the Royal Society of London. Series B: Biological Sciences, 267(1441), 363-369. DOI: 10.1098/ rspb.2000.1010.

Vinigradova, O. (2012). Cyanoprokaryota in hyperhaline ecosystems of Ukraine (in Ukrainian). Kyiv: Alterpres.

Whitton, B.A. (Ed.) (2012). Ecology of cyanobacteria II: Their diversity in space and time. Netherlands: Springer. DOI: 10.1007/978-94-007-3855-3.

Williams, C.B. (1947). The generic relations of species in small ecological communities. The Journal of Animal Ecology, 16(1), 11. DOI: 10.2307/1502.

Williams, C.B. (1949). Jaccard's generic coefficient and coefficient of floral community, in relation to the logarithmic series and the index of diversity. Annals of Botany, 13(49), 53-58. DOI: 10.2307/42908473.

Williams, C.B. (1964). Patterns in the balance of nature and related problems in quantitative ecology. London: Academic Press. DOI: 10.1002/ iroh.19650500209.

Zaverukha, B.V. (1985). Flora of Ukraine. In Nature of the Ukrainian SSR Plant world (pp. 208). Kyiv: Naukova Dumka. 
Appendix 1. Information on objects with known area and known flora species diversity.

\begin{tabular}{|c|c|c|c|c|c|}
\hline Object & Area, ha & Species & Genus & Families & Source \\
\hline Ukraine & $60,362,800$ & 4523 & 1052 & 156 & Zaverukha (1985) \\
\hline Dnipropetrovsk and Zaporizhia Region & $5,910,600$ & 1944 & 645 & 139 & Tarasov (2012) \\
\hline Dnipropetrovska Oblast & $3,192,300$ & 1714 & 615 & 126 & Tarasov (2012) \\
\hline Zaporizhia Region & $2,718,300$ & 1522 & 548 & 120 & Tarasov (2012) \\
\hline Nizhnedneprovska arena & 181,000 & 595 & 318 & 50 & Melnychuk and Trochymenko (2017) \\
\hline Carpathian BR & 58,035 & 1364 & 497 & 112 & Onyshchenko and Andrienko (2012a) \\
\hline 'Azovo-Syvasky' NNP & 52,154 & 716 & 325 & 81 & Onyshchenko and Andrienko (2012b) \\
\hline Danube BR & 50,252 & 955 & 380 & 101 & Onyshchenko and Andrienko (2012a) \\
\hline NNP Synevyr & 42,704 & 890 & 398 & 104 & Onyshchenko and Andrienko (2012b) \\
\hline NNP Holy Mountains & 40,448 & 1160 & 480 & 116 & Onyshchenko and Andrienko (2012b) \\
\hline NNP Skolivski Beskydy & 35,684 & 844 & 395 & 103 & Onyshchenko and Andrienko (2012b) \\
\hline Crimean NR & 34,563 & 1348 & 532 & 110 & Onyshchenko and Andrienko (2012a) \\
\hline Ascania-Nova BR & 33,307 & 509 & 265 & 63 & Onyshchenko and Andrienko (2012a) \\
\hline Hetman NPP & 23,360 & 635 & 376 & 105 & Onyshchenko and Andrienko (2012b) \\
\hline 'Polissya' NR & 20,104 & 602 & 333 & 92 & Onyshchenko and Andrienko (2012a) \\
\hline NNP Velykyi Lug & 16,756 & 410 & 259 & 76 & Onyshchenko and Andrienko (2012b) \\
\hline ‘Desnsko-Starohutsky’ NPP & 16,215 & 798 & 402 & 109 & Onyshchenko and Andrienko (2012b) \\
\hline Pryazovskyi NNP & 16,073 & 1060 & 418 & 92 & Onyshchenko and Andrienko (2012b) \\
\hline North Podillya NPP & 15,587 & 1100 & 470 & 113 & Onyshchenko and Andrienko (2012b) \\
\hline Yalta Mountain-Forest NR & 14,523 & 1363 & 509 & 100 & Onyshchenko and Andrienko (2012a) \\
\hline ‘Gomilshanskie Woodlands’ NPP & 14,314 & 900 & 320 & 100 & Onyshchenko and Andrienko (2012b) \\
\hline ‘Gadyach’ RLP & 12,803 & 947 & 448 & 114 & Khannanova (2015) \\
\hline NPP Vyzhnytsky & 11,238 & 683 & 235 & 96 & Onyshchenko and Andrienko (2012b) \\
\hline NNP Dzriylgatsky & 10,000 & 500 & 252 & 72 & Onyshchenko and Andrienko (2012b) \\
\hline NNP 'Kremeneckì Gory’ & 6951 & 950 & 320 & 95 & Onyshchenko and Andrienko (2012b) \\
\hline NNP 'Meotyda' & 6343 & 731 & 324 & 84 & Onyshchenko and Andrienko (2012b) \\
\hline Gorgan NR & 5344 & 451 & 266 & 79 & Onyshchenko and Andrienko (2012a) \\
\hline ‘Dnipro-Orilsky’ NR & 3766 & 670 & 360 & 95 & Onyshchenko and Andrienko (2012a) \\
\hline Chersky NR & 2975 & 760 & 382 & 103 & Onyshchenko and Andrienko (2012a) \\
\hline Karadag NR & 2874 & 1175 & 477 & 103 & Onyshchenko and Andrienko (2012a) \\
\hline Ukrainian steppe NR & 2768 & 604 & 295 & 75 & Onyshchenko and Andrienko (2012a) \\
\hline Rotochia NR & 2084 & 944 & 457 & 122 & Onyshchenko and Andrienko (2012a) \\
\hline NR Opksky & 1592 & 452 & 244 & 62 & Onyshchenko and Andrienko (2012a) \\
\hline $\begin{array}{l}\text { NR 'Chalky Flora' (Department } \\
\text { of the Ukrainian Steppe Nature Reserve) }\end{array}$ & 1134 & 490 & 274 & 65 & Onyshchenko and Andrienko (2012a) \\
\hline NR Kazantip & 450 & 617 & 301 & 71 & Onyshchenko and Andrienko (2012a) \\
\hline $\begin{array}{l}\text { NR 'Stone Graves' (Department } \\
\text { of the Ukrainian Steppe Nature Reserve) }\end{array}$ & 389 & 470 & 252 & 59 & Onyshchenko and Andrienko (2012a) \\
\hline $\begin{array}{l}\text { NR 'Mykhailivska Tsilina' (Department } \\
\text { of the Ukrainian Steppe Nature Reserve) }\end{array}$ & 202 & 531 & 287 & 66 & Onyshchenko and Andrienko (2012a) \\
\hline
\end{tabular}

